\title{
Disease model organism for Parkinson disease: Drosophila melanogaster
}

\author{
Binod Aryal \& Youngseok Lee \\ Department of Bio and Fermentation Convergence Technology, Kookmin University, BK21 PLUS Project, Seoul 02707, Korea
}

\begin{abstract}
Parkinson's disease (PD) is a common neurodegenerative disorder characterized by selective and progressive loss of dopaminergic neurons. Genetic and environmental risk factors are associated with this disease. The genetic factors are composed of approximately 20 genes, such as SNCA, parkin, PTEN-induced kinase1 (pink1), leucine-rich repeat kinase 2 (LRRK2), ATP13A2, MAPT, VPS35, and DJ-1, whereas the environmental factors consist of oxidative stress-induced toxins such as 1-methyl-4-phenyl-1, 2, 3, 6-tetrahydropyridine (MPTP), rotenone, and paraquat. The analyses of their functions and mechanisms have provided important insights into the disease process, which has demonstrated that these factors cause oxidative damage and mitochondrial dysfunction. The most invaluable studies have been performed using disease model organisms, such as mice, fruit flies, and worms. Among them, Drosophila melanogaster has emerged as an excellent model organism to study both environmental and genetic factors and provide insights to the pathways relevant for PD pathogenesis, facilitating development of therapeutic strategies. In this review, we have focused on the fly model organism to summarize recent progress, including pathogenesis, neuroprotective compounds, and newer approaches. [BMB Reports 2019; 52(4): 250-258]
\end{abstract}

\section{INTRODUCTION}

Parkinson disease (PD) is the second-most common human neurodegenerative (ND) disorder after Alzheimer's disease. The pathological features involve slow degeneration of the dopaminergic neurons in the substantia nigra $(\mathrm{SN})$ and formation of intracytoplasmic Lewy body (LB) inclusion structures. Moreover, PD is characterized by neuronal

*Corresponding author. Tel: +82-2-910-5734; Fax: +82-2-9105739; E-mail: ylee@koomin.ac.kr

https://doi.org/10.5483/BMBRep.2019.52.4.204

Received 3 September 2018, Revised 18 October 2018, Accepted 29 November 2018

Keywords: Environmental toxins, Genetic factors, Mitochondrial dysfunction, Oxidative stress, Parkinson's disease inclusions composed of abnormal $\alpha$-synuclein, which is generally referred to as the Lewy-related pathology (1). It leads to cellular toxicity and, eventually, PD pathogenesis. Most PD cases are idiopathic, which appears to be involved in multiple processes such as neuroinflammation, excitotoxicity, oxidative stress, environmental toxins, and accumulation of misfolded proteins from proteasome impairment (2).

Over the past 15 years, several gene mutations have been definitively shown to mediate familial PD. For instance, SNCA mutations (encoding $\alpha$-synuclein to PARK1 (3) and PARK4 (4), LRRK2 (PARK8) (5), VPS35 (PARK17) (6), HtrA2 (PARK13) (7), and EIG4G1 (PARK18) (8) cause autosomal dominant forms of PD. Moreover, mutations in parkin (PARK2) (9), DJ-1 (PARK7) (10), pink1 (PARK6) (11), DNAJC6 (PARK19) (12), SYANJ1 (PARK20) (13), and ATP13A2 (PARK9) (14) are associated with autosomal-recessive forms of PD.

Mitochondrial dysfunction and oxidative stress are the symptoms of PD pathogenesis (15). Recent demonstrations that pink1, parkin, and DJ-1 play crucial roles in mitochondrial function and resistance to oxidative stress, reinforcing the central importance of these themes in PD pathogenesis. Moreover, it allows us to understand PD processes at the molecular and cellular levels.

Drosophila melanogaster, commonly known as the fruit fly, is a powerful organism for modeling human ND diseases. Nearly $75 \%$ of all human disease genes have Drosophila homologues (16). Drosophila models have successfully provided valuable insights into the elucidation of pathomechanisms and development of therapies for neurodegenerative diseases. The causal relationship among PD abnormalities, such as dopaminergic cell degeneration, inclusion body formation, and locomotion dysfunction, have been elucidated with the expression of $\alpha$-synuclein in Drosophila models (17). Most recently, SPG7 mutants showed a short life span, progressive locomotion defects, and sensitivity to chemical and environmental stressors (18). Here, we reviewed in detail how these genetic and environmental factors are involved in PD with model organisms, especially $D$. melanogaster.

\section{DOPAMINERGIC (DA) NEURONS IN PARKINSON DISEASE}

PD is characterized by the death of DA neurons in the 
substantia nigra $(\mathrm{SN})$ region of the brain. Oxidative stress plays a key role in the DA neurons' degeneration. The susceptibility of the brain, especially the $\mathrm{SN}$ to oxidative stress, is augmented by various factors such as high oxygen demands, higher rates of oxidative metabolism, lower levels of protective antioxidant system, and an abundant neuronal network (19). These pathways produce abundant quantities of ROS species. Moreover, mitochondrial dysfunction and the impaired protein degradation pathway align to the degeneration of dopaminergic neurons which further influence PD-related protein expressions, such as LRRK2, $\alpha$-Syn, PINK1, UCH-L1, and DJ-1 (20-22). The misexpression or overexpression of the above parameters in $D$. melanogaster was examined to unscramble the root cause and mechanisms of DA neuronal loss. Therefore, studies of molecular and cellular mechanisms between mitochondrial dysfunction and different genes are essential for establishing therapeutic treatment for PD.

\section{MITOCHONDRIAL DYSFUNCTION IN PD}

Most mitochondrial dysfunction results from damage to complex I or nicotinamide adenine dinucleotide phosphate (NADH): ubiquinone oxidoreductase - which forms a part of the oxidative phosphorylation system (23). PD pathogenesis results from impairment to complex I and complex I-mediated dopaminergic cell death resulting from Bax transcription activation (24). Furthermore, a clear correlation exists between ND diseases and impaired electron transport chain function. Iron containing cytochromes-associated movement plays a particularly prominent role in the mitochondrial membrane (25). As a result of this dysfunction, increased free radicals have been recorded, which is harmful to the proper functioning of cells. Oxidants, including hydrogen peroxide and superoxide radicals, are produced as byproducts of oxidative phosphorylation, making the mitochondria the main site of ROS generation within a cell. However, in pathological situations where mitochondrial respiratory defects occur, the amount of ROS produced by the electron transport chain increases dramatically, swamping the antioxidant protection mechanisms. PD has been shown to produce these conditions (Fig. 1). Evidence that oxidative stressors, such as ROS, are the culprits in these mitochondrial dysfunctions has recently emerged. The generation of oxidizing agents, such as hydrogen peroxide or superoxide, recapitulates the mitochondrial dysfunction (26).

Excess free radicals are scavenged by enzymes such as glutathione peroxidase, catalase, and superoxide dismutase in normal mitochondria. However, when ROS build up, they interact with the membrane lipids and proteins, altering their conformations and, ultimately, disrupting their functioning. Furthermore, complex I inhibitors, like MPTP or rotenone, demonstrate preferential cytotoxicity to the DA neurons (27). The MPP ${ }^{+}$(oxidized form of MPTP that is toxic) accumulates in the mitochondria, where it inhibits complex $\mathrm{I}$ in the mitochondrial electron transport chain complex (METC), thereby disrupting the flow of electrons along the METC (Fig. 1). This event results in decreased ATP production and increased ROS generation (28). Similar to MPTP, rotenone is another mitochondrial complex I inhibitor. Interestingly, rotenone toxicity is involved in oxidative damage to proteins and Lewy body-like inclusions (29). Other evidence for mitochondrial dysfunction related to oxidative stress and DA cell damage comes from findings that mutations in protein genes like $\alpha$-synuclein, parkin, DJ-1, or pink1 are linked to the familial forms of PD (Fig. 1). Indeed, the latest study provides evidence that elevated mitochondrial $\mathrm{Ca}^{2+}$ is responsible for mitochondrial damage and neuronal death, which is controlled by a mitochondrial trafficking protein, Miro (30). The intercorrelated role of these proteins on mitochondrial dynamics reveals a common function in the mitochondrial stress response, which may provide a significant physiological basis for PD pathology (31).

\section{MOLECULAR MODELS FOR PARKINSON DISEASE (Table 1)}

SNCA ( $\alpha$-synuclein: $\alpha S)$

SNCA encodes a small protein called $\alpha$-synuclein. $\alpha$-Synuclein



Fig. 1. Toxins and genetic factors responsible for PD. Schematic illustrations for related genes of PD and toxins in the mitochondria. 
Parkinson disease: Drosophila melanogaster

Binod Aryal and Youngseok Lee

Table 1. Parkinson's disease and their phenotypic expressions in animal models

\begin{tabular}{|c|c|c|}
\hline PD gene/locus & Mammalian/mouse & Drosophila melanogaster \\
\hline SNCA/PARK1 & $\begin{array}{l}\text { Expression of Human } \alpha \text {-Syn (A53T): } \uparrow \text { Accumulation of } \\
\alpha \text {-synuclein, ND and leading to cell death (75). } \\
\text { Expression of Human } \alpha \text {-Syn (A30P): Progressive motor } \\
\text { disorder accompanied by accumulation of } \alpha \text {-synuclein in } \\
\text { the soma and neurite (76). }\end{array}$ & $\begin{array}{l}\text { Expression of Human } \alpha \text {-Syn (A30P and A53T) in } \\
\text { pan-neuron: Dopaminergic cell degeneration, LB } \\
\text { inclusion formation and locomotor dysfunction (17). }\end{array}$ \\
\hline parkin/PARK2 & $\begin{array}{l}\text { Expression of C-terminally truncated parkin in DA neuron: } \\
\text { Motor deficit, nigrostriatal degeneration, } \alpha \text {-synuclein } \\
\text { accumulation (77). }\end{array}$ & $\begin{array}{l}\text { KO mutants: } \downarrow \text { Lifespan and locomotion, and male } \\
\text { sterility (40). } \\
\text { Loss of proper morphology of DA neurons and deficit in } \\
\text { motor function ( } 42 \text { ). }\end{array}$ \\
\hline PARK3 & $\begin{array}{l}\text { ND in SN of brain and LB formation, presence of } \\
\text { neurofibrillary tangles and Alzheimer plaques (78). }\end{array}$ & - \\
\hline SNCA/PARK4 & $\begin{array}{l}\text { Nigral degeneration with } L B \text {, vacuoles in neurons of the } \\
\text { hippocampus and other brain parts (78). }\end{array}$ & - \\
\hline UCH-L1/PARK5 & $\begin{array}{l}\text { Rotenone induced mouse models: S-Nitrosylation of } \\
\text { UCH-L1, } \uparrow \alpha \text {-synuclein aggregation (79). }\end{array}$ & $\begin{array}{l}\text { KD mutants: } \downarrow \text { Dopamine in the brain results in } \\
\text { locomotor dysfunction }(80) \text {. }\end{array}$ \\
\hline pink1/PARK6 & $\begin{array}{l}\text { KO mouse: Impairment in hindlimb and forelimb steps } \\
\text { (81). }\end{array}$ & $\begin{array}{l}\text { KO mutants: Mitophagy of flight muscle cells and } \\
\text { dopaminergic neuron with aging (82). }\end{array}$ \\
\hline DJ-1/PARK7 & KO mouse: Loss of DA neurons in SN of brain (83). & $\begin{array}{l}\text { DJ-1 } 1 \beta \text { mutant: } \downarrow \text { Climbing activity (41). } \\
\text { Exhibit taste impairment and memory defect (59). }\end{array}$ \\
\hline LRRK2/PARK8 & $\begin{array}{l}\text { Overexpression of } \angle R R K 2^{R 1441 C} \text { : Progressive motor deficit } \\
\text { with immobility by } 10-12 \text { months (84). }\end{array}$ & $\begin{array}{l}\text { Expression of RNA interference of JNKK or } \\
\text { dominant-negative form of JNK increases fly survival } \\
\text { time, locomotor activity, and decrease DA neuronal } \\
\text { degeneration in } L R R K 2^{\text {C2019S }} \text { overexpression in DA } \\
\text { neurons (63). }\end{array}$ \\
\hline ATP13A2/PARK9 & $\begin{array}{l}\text { KD mouse: Impairment in lysosomal degradation, } \\
\alpha \text {-synuclein accumulation and neurotoxicity (85). }\end{array}$ & - \\
\hline Unknown/PARK10 & - & - \\
\hline GIGYF2/PARK11 & $\begin{array}{l}\text { Heterozygous Gigyf2 } 2^{+-} \text {mouse: Exhibits motor } \\
\text { dysfunction by } 12-15 \text { months (86). }\end{array}$ & KO mutants: Locomotor defects and early mortality (87). \\
\hline Unknown/PARK12 & - & - \\
\hline HtrA2/PARK13 & $\begin{array}{l}\text { KO mouse: } \downarrow \text { Climbing ability, movement disorders, and } \\
\text { tremor (88). }\end{array}$ & $\begin{array}{l}\text { KO mutants: Mitochondrial defects, loss of flight and } \\
\text { climbing ability, male infertility, and increase of } \\
\text { sensitivity to oxidative stress (89). }\end{array}$ \\
\hline PLA2G6/PARK14 & $\begin{array}{l}\text { KO mouse: Loss of DA neurons in SN and rescue by } \\
\text { feeding L-DOPA in motor dysfunction (90). }\end{array}$ & $\begin{array}{l}\text { KO mutants: Mitochondrial dysfunction and oxidative } \\
\text { stress (91). }\end{array}$ \\
\hline FBOX7/PARK15 & $\begin{array}{l}\text { KO mouse: } \downarrow \text { Proteasome activities and early-onset motor } \\
\text { deficit (92). }\end{array}$ & $\begin{array}{l}\text { Expression of FBXO7 rescues parkin mutant phenotypes, } \\
\text { including locomotors dysfunction, DA neuron losses and } \\
\text { muscle degeneration (93). }\end{array}$ \\
\hline $\begin{array}{l}R A B 7 L 1 \text { (one of the } \\
\text { candidate }\end{array}$ & $\begin{array}{l}\text { KD rodent: DA neuron degeneration as } L R R K 2 \text { mutant } \\
\text { phenotype. }\end{array}$ & $\begin{array}{l}\text { KD Mutants: DA neuron degeneration as } L R R K 2 \text { mutant } \\
\text { phenotype. }\end{array}$ \\
\hline gene)/PARK16 & $\begin{array}{l}\text { Overexpression of } R A B 7 L 1 \text { reduces } L R R K 2 \text { mutant induced } \\
\text { DA neurodegeneration (94). }\end{array}$ & $\begin{array}{l}\text { Overexpression of } R A B 7 L 1 \text { in DA neurons rescues DA } \\
\text { neurodegeneration (94). }\end{array}$ \\
\hline VPS35/PARK17 & $\begin{array}{l}\text { VPS } 35^{+-} \text {mouse: Mitochondrial fusion and cellular } \\
\text { respiration function impairments and neuronal loss (95). }\end{array}$ & $\begin{array}{l}\text { KD of VPS35: Locomotor impairments, mild compound } \\
\text { eye disorganization, and interommatidial bristleloss ( } 37 \text {. }\end{array}$ \\
\hline EIG4G1/PARK18 & $\begin{array}{l}\text { Mutation in EIG4G1 (A502V, R1205H): Impairment in } \\
\text { oxidative stress resistance (8). }\end{array}$ & - \\
\hline DNAJC6/PARK19 & $\begin{array}{l}\text { KO mouse: Early postnatal mortalities, and weight loss of } \\
\text { surviving pups (96). }\end{array}$ & $\begin{array}{l}\text { KD mutants: Loss of climbing abilities, decrease of } \\
\text { lifespan, and DA neuron death (97). }\end{array}$ \\
\hline SYNJ1/PARK20 & $\begin{array}{l}S Y N J 1^{+1-} \text { mice: Progressive PD-like behavioral alterations } \\
\text { and DA neurodegeneration (98). }\end{array}$ & $\begin{array}{l}\text { KD mutants: } \downarrow \text { Endogenous synaptic transmission at the } \\
\text { neuromuscular junction, and } 80 \% \text { reduction of evoked } \\
\text { transmission (99). }\end{array}$ \\
\hline
\end{tabular}

PD genes and their phenotypic expressions in animal models, especially Drosophila melanogaster.

PD: Parkinson's disease, UCH-L1: ubiquitin carboxyl-terminal esterase L1, PINK1: PTEN-induced putative kinase 1, LRRK2: leucine-rich repeat kinase 2, HtrA2: High temperature requirement protein A2, FBOX7: F-box protein 7, LOF: Loss of function, KD: Knockdown, KO: Knockout, DA: dopamine, $\downarrow$ : Decreased/Reduced, $\uparrow:$ Increased/Enhanced, LB: Lewy body. 
is abundant in the brain; small amounts are detected in the heart, muscles, and other tissues. PD correlates with the formation of insoluble fibrillar aggregates in the central nervous system that contain $\alpha$-synuclein (3) and misfolding of $\alpha$-synuclein resulting from point mutations in SNCA (Fig. 2A). Aggregated monomeric $\alpha$-synuclein generates $\beta$ sheet-rich oligomers, inducing selective oxidation of the ATP synthase $\beta$ subunit and mitochondrial lipid peroxidation. These oxidation events increase the probability of permeability transition pore opening, triggering mitochondrial swelling and, ultimately, cell death (32). A30P, A53T, and E46K (33) are three PD-related $\alpha S$ mutations. Among them, A30P and A53T are the most well-studied mutations. A53T transgenic mice displayed abnormally large accumulations of $\alpha$-synuclein, causing rapid neurodegeneration and leading to cell death. A30P $\alpha$-synuclein transgenic animals exhibit similar physiological and phenotypic characteristics to those found in humans, including the slow degeneration of DA neurons, formation of LB-like inclusions, and loss of locomotor functions (17). Similarly, a Drosophila-expressing A30P mutant causes a more rapid loss of climbing ability (34). Cathespin D, glucocerobrosidase, and proteinase $\mathrm{K}$ actively participate in accumulation of $\alpha$-synuclein in the brain, resulting in DA neuronal loss along with decreased locomotor activity (35-38). $\mathrm{N}$-terminal 32 amino acids of human $\alpha$-synuclein contains mitochondrial targeting signal that plays a role in the association of these proteins with the inner mitochondrial membrane. Aggregated $\alpha$-synuclein in the mitochondrial membrane of DA neurons results in complex I impairment,

A

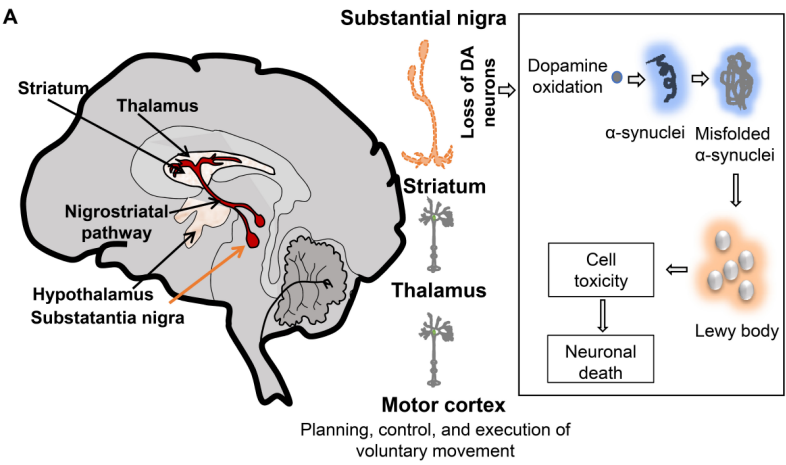

B

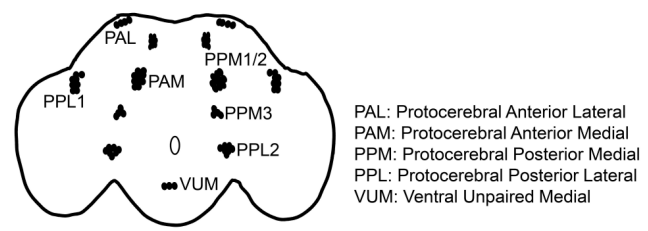

Fig. 2. Clinical presentation of pathogenesis in PD and fly dopaminergic neuronal clusters. (A) Dopaminergic neurons in the substantia nigra and PD pathology related with Lewy body. (B) Dopaminergic neuronal clusters in a fly brain. increased ROS production, and decreased mitochondrial transmembrane potential (39).

\section{parkin}

parkin mutation leads to an early onset form of $\mathrm{PD}$, and its product encodes an E3 ligase, including functional domains such as the ubiquitin-like domain and RING finger domains. The first in vivo indication that parkin regulates mitochondrial integrity arose from studies on Drosophila parkin mutants. parkin fly mutants exhibit locomotor defects, reduced longevity, male sterility, DA neurodegeneration, and mitochondrial defects in several energy-intensive tissues such as muscles and brain $(40,41)$. D. parkin null mutants display degeneration of DA neurons in the PPL1 cluster and reduced $\mathrm{TH}$ - staining in the PPM1/2 cluster (Fig. 2B), resulting in reduced DA content in the brain. D. parkin loss-of-function mutants exhibit shrinkage of DA neurons with a decrease of tyrosine hydroxylase (TH) level and locomotor defects (42).

\section{pink1}

This gene encodes a putative serine/threonine kinase with a mitochondrial targeting sequence (11). pink1 mutants possess fragmentation in mitochondrial cristae and are very susceptible to oxidative stress. pink1 mutants are characterized by reduced lifespan, locomotor defects, degenerated flight muscle, and loss of DA neurons (43). D. pink1 mutants also have a defective thorax phenotype in three-day-old flies as well as age-dependent loss of DA neurons in the PPL1 cluster at the age of 30 days (44). Furthermore, pink1 loss of function in mice models resulted in locomotor defects and degenerated DA neurons (45). These studies provide cellular and behavioral phenotypes of pink1 mutant reproducing PD phenotypes.

The pink 1 mutant flies share marked phenotypic similarities with parkin mutants. A pink1 mutant phenotype was rescued by parkin overexpression, whereas pink 1 overexpression had no effect on parkin mutant phenotypes $(46,47)$. These observations suggest that Parkin acts downstream of Pink1 in the same pathway, which is conserved between flies and mammals. Genetic epistasis analyses revealed that proteins function in the same pathway to maintain mitochondrial fidelity, although they are localized differently; pink1 localizes to the mitochondria, and parkin resides in the cytosol $(40,47$, 48). Cell studies have revealed parkin is recruited from the cytosol to depolarized mitochondria to mediate selective autophagic removal of the damaged organelle (mitophagy) (49). Furthermore, in Drosophila, pink1 directly phosphorylates parkin to control its translocation to the mitochondria (50). The above finding suggests that pink 1 and parkin act in a common pathway.

\section{DJ-1}

DJ-1 binds to the subunits of mitochondrial complex I and regulates its activity (51). It is present in the mitochondrial 
matrix and intermembranal space (52). Its translocation into the mitochondria is enhanced by oxidative stress. DJ-1 KO mice elicit nigrostriatal DA neuron loss and accumulate defective mitochondria, which can be reversed by adenovirusmediated D/-1 overexpression; this phenomenon demonstrates $D J-1$ 's specific role in mitochondrial function (53).

DJ-1 encodes a highly conserved protein belonging to the Thij/PfPI superfamily of molecular chaperones (54). Two DJ-1 orthologs exist in Drosophila: $D J-1 \alpha$ and $D J-1 \beta$. DJ-1 $\alpha$ is predominantly expressed in the male testis and, at a lower level, in the brain than $D J-1 \beta$. DJ-1 $\alpha$ exhibits a role in oxidative stress, generating DA neurodegeneration, although the $D J-1 \beta$ mutant contributes more to DA neuronal degeneration (55). DJ-1 $\beta$ decreases climbing ability (41) and increases sensitivity to environmental toxins such as $\mathrm{H}_{2} \mathrm{O}_{2}$, paraquat, and rotenone (56). DJ-1 $\beta$ loss of function results in accumulated ROS in adult brains, elevated levels of lipid peroxidation, and an increased catalase enzymatic activity (57). In Drosophila, both the aging process and oxidation challenge promote $D /-1 \beta$ overoxidation at cysteine 104 (which is analogous to cysteine 106 in human DJ-1) which, in turn, irreversibly inactivates the protein DJ-1 (58). Aged flies demonstrate further vulnerability to oxidative stress, which suggests that $D J-1$ 's protective function against oxidative stress could be progressively lost through aging, increasing the risk of DA neuron loss. Recently, our group reported that the $D J-1 \beta$ mutant has low sugar sensitivity and reduced taste-associative memory (59), which are relevant phenotypes because $>30 \%$ of PD patients have dementia. Our group also showed recovery from reduced memory defect by feeding health supplements such as omija. The fly model organism can be used for drug discovery in behavioral as well as cellular studies.

\section{LRRK2}

The most common form of sporadic PD occurs due to mutations in the gene encoding $L R R K 2$, which comprises a large domain GTPase and kinase activity. LRRK2 has been associated with a diverse set of cellular functions and signaling pathways, including mitochondrial function, vesicle trafficking, together with endocytosis, retromer complex modulation, and autophagy (60). The study in mice showed that the degeneration of dopamine neurons is enhanced due to combined effects of LRRK2G2019S mutation with environmental toxins such as MPTP (61). The overexpression of LRRK2 or LRRK2-G2019S lead to retinal degeneration, selective loss of DA neurons, decreased climbing activity, and early mortality in flies (62). LRRK2-induced neuronal degeneration is mediated by hemipterous (hep or JNKK). The expression of RNA interference of JNKK or dominant-negative form of JNK, a downstream kinase of JNKK, increases fly survival, locomotor activity, and decreases DA neuronal degeneration in LRRK2-G2019S mutant (63).

\section{ENVIRONMENTAL RISK FACTORS FOR PD}

\section{MPTP}

MPTP is the most commonly used toxin to generate a PD model. It is one of the first models to link the inhibition of mitochondria complex I to PD (64). Several animal species, such as sheep, cats, mice, rats, and monkeys have been treated with MPTP to recapitulate the phenotype of a PD model. Both monkeys and mice treated with MPTP have shown selectively progressive loss of DA neurons, but no LBs (65). Loss of DA neurons leads to reduced motor abilities, although there are no LBs. MPTP induces a high level of NO in flies. Resveratrol decreases MPTP-mediated oxidative stress in flies and increases their life span. Therefore, resveratrol can be used as a therapeutic agent against PD (66), which indicates that a MPTP toxin-induced model in D. melanogaster is a useful tool for PD pathophysiology.

\section{Rotenone and paraquat}

Several studies have looked at rotenone and paraquat (PQ) (a proposed mitochondrial complex I inhibitor) in Drosophila to investigate the susceptibility of PD genetic models and their role in neuronal cell death. Not only do these models induce DA neuron loss, but also show evidence of behavioral and histological changes, completing the pathological picture of PD (67). Paraquat causes oxidative stress in cells through the ROS generation. Rotenone blocks the mitochondrial electron transport chain through inhibition of complex $\mathrm{I}$, as seen in MPTP. Rotenone also blocks mitosis and inhibits cell proliferation, which is caused by the perturbation of microtubule assembly and decreases the GTP hydrolysis rate (68). Chronic systemic exposure to rotenone in rats led to the development of several features of PD, including nigrostriatal DA degeneration. This model has been shown to reproduce almost all PD features, including the formation of intracellular inclusions that resemble LB (69).

\section{THERAPEUTICS APPROACH IN PARKINSON DISEASE}

Vitamin $K_{2}$ acts as an electron carrier and enhances ATP production in the mitochondria. Defective mitochondria are also found in Parkinson's patients with a pink1 or parkin mutation. Vitamin $K_{2}$ may offer hope for a new PD treatment (70). Vitamin $K_{2}$ is essential to electron transfer in Drosophila mitochondria. Heix mutants show severe mitochondrial defects that are rescued by vitamin $K_{2}$, which serves as a mitochondrial electron carrier, helping to maintain normal ATP production. A major breakthrough in PD drug development was L-dopa, which protects the brain from oxidative stress and free radicals (71). Most pharmacological approaches to PD treatment are symptomatic and target the nigrostriatal dopaminergic pathway. The gold-standard drug is L-dopa-a precursor of dopamine-which crosses the blood-brain barrier and is converted to dopamine. Other drugs 
are used as monotherapy or combined with L-dopa to enhance its efficacy, including dopamine receptor agonists, catecholO-methytransferase (COMT) inhibitors, and monoamine oxidase (MAO) inhibitors (72). Zinc is an essential trace metal and a component of several enzymes and transcriptional regulators. Unlike copper and iron, zinc is not redox-active and, under most conditions, it serves as an antioxidant. The condition of parkin mutants raised on zinc-supplemented food is greatly improved. Parkin mutants perform best at high zinc concentrations, where controls begin to show adverse effects as a result of the metal supplement. This is manifested in a higher frequency of reaching adulthood, extended lifespan, and improved motor abilities (73).

\section{CONCLUSION AND FUTURE PERSPECTIVE}

Drosophila mutants and transgenic models have been used to study the genetics and environmental factors responsible for PD. More than 20 genes are associated with PD, which shows interaction between genetics and environmental factors. The common endpoint of gene and toxins are believed to initiate mitochondrial dysfunction, which results in lower ATP and oxidative stress. Various antioxidants, such as zinc and vitamin $\mathrm{K}_{2}$, have shown good medicinal value in PD. Similarly, omija feeding has also helped resolve taste memory problems and learning defects. Until now, most studies have focused on mitochondrial dysfunction and correlated genes. In addition to mitochondrial dysfunction and oxidative stress, endoplasmic reticulum (ER) stress is another demanding model to study PD pathogenesis in D. melanogaster. ER stress can be reduced with piperine, which increases mesencephalic astrocytederived neurotrophic factor expression that ameliorates spinocerebrellar ataxia 17 (SCA17)-associated neuropathology in the TBP-105Q knock-in mouse model (74). The study of piperine's involvement in controlling neurodegeneration would be a fascinating approach for effective prophylaxis. More powerful clinical treatments than L-dopa (a precursor of dopamine) are needed for PD patients, especially in an aging society.

\section{ACKNOWLEDGEMENTS}

We thank Jeeyoung Lee for valuable comments. B.A. was supported by the Global Scholarship Program for Foreign Graduate Students at Kookmin University in Korea. This work is supported by grants to Y.L. from the Basic Science Research Program of the National Research Foundation of Korea (NRF) funded by the Ministry of Education (NRF-2016R1D1A1B 03931273 and NRF-2018R1A2B6004202).

\section{CONFLICTS OF INTEREST}

The authors have no conflicting interests.

\section{REFERENCES}

1. Forno LS (1996) Neuropathology of Parkinson's disease. J Neuropathol Exp Neurol 55, 259-272

2. Whitton $P$ (2007) Inflammation as a causative factor in the aetiology of Parkinson's disease. Br J Pharmacol 150, 963-976

3. Polymeropoulos MH, Lavedan C, Leroy E et al (1997) Mutation in the $\alpha$-synuclein gene identified in families with Parkinson's disease. Science 276, 2045-2047

4. Singleton A, Farrer M, Johnson J et al (2003) $\alpha$-Synuclein locus triplication causes Parkinson's disease. Science 302, 841-841

5. Zimprich A, Biskup S, Leitner P et al (2004) Mutations in LRRK2 cause autosomal-dominant parkinsonism with pleomorphic pathology. Neuron 44, 601-607

6. Zimprich A, Benet-Pagès A, Struhal W et al (2011) A mutation in VPS35, encoding a subunit of the retromer complex, causes late-onset Parkinson disease. Am J Hum Genet 89, 168-175

7. Wakabayashi K and Takahashi H (2007) Pathology of familial Parkinson's disease. Brain Nerve 59, 851-864

8. Chartier-Harlin M-C, Dachsel JC, Vilariño-Güell C et al (2011) Translation initiator EIF4G1 mutations in familial Parkinson disease. Am J Hum Genet 89, 398-406

9. Kitada T, Asakawa S, Hattori N et al (1998) Mutations in the parkin gene cause autosomal recessive juvenile parkinsonism. Nature 392, 605-608

10. Bonifati V, Rizzu P, Squitieri F et al (2003) DJ-1 (PARK7), a novel gene for autosomal recessive, early onset parkinsonism. Neurol Sci 24, 159-160

11. Valente EM, Abou-Sleiman PM, Caputo V et al (2004) Hereditary early-onset Parkinson's disease caused by mutations in PINK1. Science 304, 1158-1160

12. Köroğlu Ç, Baysal L, Cetinkaya $M$, Karasoy $H$ and Tolun $A$ (2013) DNAJC6 is responsible for juvenile parkinsonism with phenotypic variability. Parkinsonism Relat Disord 19, 320-324

13. Quadri M, Fang M, Picillo M et al (2013) Mutation in the SYNJ1 Gene Associated with Autosomal Recessive, Early-Onset P arkinsonism. Hum Mutat 34, 1208-1215

14. Ramirez A, Heimbach A, Gründemann J et al (2006) Hereditary parkinsonism with dementia is caused by mutations in ATP13A2, encoding a lysosomal type 5 P-type ATPase. Nat Genet 38, 1184-1190

15. Greenamyre JT and Hastings TG (2004) Parkinson'sdivergent causes, convergent mechanisms. Science 304, 1120-1122

16. Bilen J and Bonini NM (2005) Drosophila as a model for human neurodegenerative disease. Annu Rev Genet 39, 153-171

17. Feany MB and Bender WW (2000) A Drosophila model of Parkinson's disease. Nature 404, 394-398

18. Pareek G, Thomas RE and Pallanck LJ (2018) Loss of the Drosophila m-AAA mitochondrial protease paraplegin results in mitochondrial dysfunction, shortened lifespan, and neuronal and muscular degeneration. Cell Death Dis 9, 304

19. Kroemer G, Galluzzi L and Brenner C (2007) Mitochondrial membrane permeabilization in cell death. 
Physiol Rev 87, 99-163

20. Kann O and Kovács R (2007) Mitochondria and neuronal activity. Am J Physiol Cell Physiol 292, C641-C657

21. Mosharov EV, Larsen KE, Kanter E et al (2009) Interplay between cytosolic dopamine, calcium, and $\alpha$-synuclein causes selective death of substantia nigra neurons. Neuron 62, 218-229

22. Dehay B, Bourdenx M, Gorry P et al (2015) Targeting $\alpha$-synuclein for treatment of Parkinson's disease: mechanistic and therapeutic considerations. Lancet Neurol 14, 855-866

23. Blum D, Torch $\mathrm{S}$, Lambeng $\mathrm{N}$ et al (2001) Molecular pathways involved in the neurotoxicity of 6-OHDA, dopamine and MPTP: contribution to the apoptotic theory in Parkinson's disease. Prog Neurobiol 65, 135-172

24. Perier C, Bové J, Wu D-C et al (2007) Two molecular pathways initiate mitochondria-dependent dopaminergic neurodegeneration in experimental Parkinson's disease. Proc Natl Acad Sci U S A 104, 8161-8166

25. Abou-Sleiman PM, Muqit MM and Wood NW (2006) Expanding insights of mitochondrial dysfunction in Parkinson's disease. Nat Rev Neurosci 7, 207-219

26. Trushina E and McMurray C (2007) Oxidative stress and mitochondrial dysfunction in neurodegenerative diseases. Neuroscience 145, 1233-1248

27. Blesa J and Przedborski S (2014) Parkinson's disease: animal models and dopaminergic cell vulnerability. Front Neuroanat 8, 155

28. Mizuno Y, Sone N and Saitoh T (1987) Effects of 1-methyl4-phenyl-1, 2, 3, 6-tetrahydropyridine and 1-methyl-4phenylpyridinium ion on activities of the enzymes in the electron transport system in mouse brain. J Neurochem 48, 1787-1793

29. Betarbet R, Sherer TB, MacKenzie G, Garcia-Osuna M, Panov AV and Greenamyre JT (2000) Chronic systemic pesticide exposure reproduces features of Parkinson's disease. Nat Neurosci 3, 1301-1306

30. Lee K-S, Huh S, Lee S et al (2018) Altered ER-mitochondria contact impacts mitochondria calcium homeostasis and contributes to neurodegeneration in vivo in disease models. Proc Natl Acad Sci U S A 115, E8844-E8853

31. Norris KL, Hao R, Chen L-F et al (2015) Convergence of parkin, PINK1 and $\alpha$-synuclein on stress-induced mitochondrial morphological remodelling. J Neurochem 290, 13862-13874

32. Ludtmann $\mathrm{MH}$, Angelova PR, Horrocks MH et al (2018) $\alpha$-synuclein oligomers interact with ATP synthase and open the permeability transition pore in Parkinson's disease. Nat Commun 9, 2293

33. Blandini $\mathrm{F}$ and Armentero MT (2012) Animal models of Parkinson's disease. FEBS J 279, 1156-1166

34. Chen AY, Xia S, Wilburn P and Tully T (2014) Olfactory deficits in an alpha-synuclein fly model of Parkinson's disease. PLoS One 9, e97758

35. Khair A, Salema B, Dhanushkodi NR et al (2018) Silencing of Glucocerebrosidase Gene in Drosophila Enhances the Aggregation of Parkinson's Disease Associated $\alpha$-Synuclein Mutant A53T and Affects Locomotor Activity. Front Neurosci 12, 81

36. Davis MY, Trinh K, Thomas RE et al (2016) Glucocerebro- sidase deficiency in Drosophila results in $\alpha$-synucleinindependent protein aggregation and neurodegeneration. PLoS Genet 12, e1005944

37. Miura E, Hasegawa T, Konno M et al (2014) VPS35 dysfunction impairs lysosomal degradation of $\alpha$-synuclein and exacerbates neurotoxicity in a Drosophila model of Parkinson's disease. Neurobiol Dis 71, 1-13

38. Suzuki M, Fujikake N, Takeuchi T et al (2015) Glucocerebrosidase deficiency accelerates the accumulation of proteinase K-resistant $\alpha$-synuclein and aggravates neurodegeneration in a Drosophila model of Parkinson's disease. Hum Mol Genet 24, 6675-6686

39. Devi L, Raghavendran V, Prabhu BM, Avadhani NG and Anandatheerthavarada HK (2008) Mitochondrial import and accumulation of $\alpha$-synuclein impair complex $\mathrm{I}$ in human dopaminergic neuronal cultures and Parkinson disease brain. J Biol Chem 283, 9089-9100

40. Greene JC, Whitworth AJ, Kuo I, Andrews LA, Feany MB and Pallanck LJ (2003) Mitochondrial pathology and apoptotic muscle degeneration in Drosophila parkin mutants. Proc Natl Acad Sci U S A 100, 4078-4083

41. Park J, Kim SY, Cha G-H, Lee SB, Kim S and Chung J (2005) Drosophila DJ-1 mutants show oxidative stress-sensitive locomotive dysfunction. Gene 361, 133-139

42. Cha G-H, Kim S, Park J et al (2005) Parkin negatively regulates JNK pathway in the dopaminergic neurons of Drosophila. Proc Natl Acad Sci U S A 102, 10345-10350

43. Yang Y, Gehrke S, Imai $Y$ et al (2006) Mitochondrial pathology and muscle and dopaminergic neuron degeneration caused by inactivation of Drosophila Pink1 is rescued by Parkin. Proc Natl Acad Sci U S A 103, 10793-10798

44. Lehmann S, Jardine J, Garrido-Maraver J, Loh SH and Martins LM (2017) Folinic acid is neuroprotective in a fly model of Parkinson's disease associated with pink1 mutations. Matters 3, e201702000009

45. Moisoi N, Fedele V, Edwards J and Martins LM (2014) Loss of PINK1 enhances neurodegeneration in a mouse model of Parkinson's disease triggered by mitochondrial stress. Neuropharmacology 77, 350-357

46. Clark IE, Dodson MW, Jiang C et al (2006) Drosophila pink1 is required for mitochondrial function and interacts genetically with parkin. Nature 441, 1162

47. Park J, Lee SB, Lee S et al (2006) Mitochondrial dysfunction in Drosophila PINK1 mutants is complemented by parkin. Nature 441, 1157

48. Clark IE, Dodson MW, Jiang C et al (2006) Drosophila pink1 is required for mitochondrial function and interacts genetically with parkin. Nature 441, 1162-1166

49. Narendra D, Tanaka A, Suen D-F and Youle RJ (2008) Parkin is recruited selectively to impaired mitochondria and promotes their autophagy. J Cell Biol 183, 795-803

50. Kim Y, Park J, Kim S et al (2008) PINK1 controls mitochondrial localization of Parkin through direct phosphorylation. Biochem Biophys Res Commun 377, 975-980

51. Hayashi T, Ishimori C, Takahashi-Niki K et al (2009) DJ-1 binds to mitochondrial complex $\mathrm{I}$ and maintains its activity. Biochem Biophys Res Commun 390, 667-672 
52. Zhang L, Shimoji M, Thomas B et al (2005) Mitochondrial localization of the Parkinson's disease related protein DJ-1: implications for pathogenesis. Hum Mol Genet 14, 2063-2073

53. Heo JY, Park JH, Kim SJ et al (2012) DJ-1 null dopaminergic neuronal cells exhibit defects in mitochondrial function and structure: involvement of mitochondrial complex I assembly. PLoS One 7, e32629

54. Lucas JI and Marín I (2006) A new evolutionary paradigm for the Parkinson disease gene DJ-1. Mol Biol Evol 24, 551-561

55. Menzies FM, Yenisetti SC and Min K-T (2005) Roles of Drosophila DJ-1 in survival of dopaminergic neurons and oxidative stress. Curr Biol 15, 1578-1582

56. Meulener $M$, Whitworth AJ, Armstrong-Gold CE et al (2005) Drosophila DJ-1 mutants are selectively sensitive to environmental toxins associated with Parkinson's disease. Curr Biol 15, 1572-1577

57. Irrcher I, Aleyasin H, Seifert E et al (2010) Loss of the Parkinson's disease-linked gene DJ-1 perturbs mitochondrial dynamics. Hum Mol Genet 19, 3734-3746

58. Meulener MC, $\mathrm{Xu} \mathrm{K}$, Thomson L, Ischiropoulos $\mathrm{H}$ and Bonini NM (2006) Mutational analysis of DJ-1 in Drosophila implicates functional inactivation by oxidative damage and aging. Proc Natl Acad Sci U S A 103, 1251712522

59. Poudel S and Lee Y (2018) Impaired Taste Associative Memory and Memory Enhancement by Feeding Omija in Parkinson's Disease Fly Model. Mol Cells 41, 646-652

60. Wallings R, Manzoni C and Bandopadhyay R (2015) Cellular processes associated with LRRK2 function and dysfunction. FEBS J 282, 2806-2826

61. Karuppagounder SS, Xiong Y, Lee $Y$ et al (2016) LRRK2 G2019S transgenic mice display increased susceptibility to 1-methyl-4-phenyl-1, 2, 3, 6-tetrahydropyridine (MPTP)mediated neurotoxicity. J Chem Neuroanat 76, 90-97

62. Liu Z, Wang X, Yu Y et al (2008) A Drosophila model for LRRK2-linked parkinsonism. Proc Natl Acad Sci U S A 105, 2693-2698

63. Yang D, Thomas JM, Li T, Lee Y, Liu Z and Smith W (2017) Drosophila hep pathway mediates Lrrk2-induced neurodegeneration. Biochem Cell Biol 96, 441-449

64. Schober A (2004) Classic toxin-induced animal models of Parkinson's disease: 6-OHDA and MPTP. Cell Tissues Res $318,215-224$

65. Tieu K (2011) A guide to neurotoxic animal models of Parkinson's disease. Cold Spring Harb Perspect Med 1, a009316

66. Abolaji AO, Adedara AO, Adie MA, Vicente-Crespo M and Farombi EO (2018) Resveratrol prolongs lifespan and improves 1-methyl-4-phenyl-1, 2, 3, 6-tetrahydropyridineinduced oxidative damage and behavioural deficits in Drosophila melanogaster. Biochem Biophys Res Commun 503, 1042-1048

67. Trinh K, Andrews L, Krause J et al (2010) Decaffeinated coffee and nicotine-free tobacco provide neuroprotection in Drosophila models of Parkinson's disease through an NRF2-dependent mechanism. J Neurosci 30, 5525-5532

68. Srivastava P and Panda D (2007) Rotenone inhibits mammalian cell proliferation by inhibiting microtubule assembly through tubulin binding. FEBS J 274, 4788-4801

69. Sherer TB, Betarbet R, Testa CM et al (2003) Mechanism of toxicity in rotenone models of Parkinson's disease. J Neurosci 23, 10756-10764

70. Vos M, Esposito G, Edirisinghe JN et al (2012) Vitamin K2 is a mitochondrial electron carrier that rescues pink1 deficiency. Science 336, 1306-1310

71. Mena MA, Casarejos MJ, Solano RM and de Yebenes JG (2009) Half a century of L-DOPA. Curr Top Med Chem 9, 880-893

72. Payami H and Factor SA (2014) Promise of pharmacogenomics for drug discovery, treatment and prevention of Parkinson's disease. A perspective. Neurotherapeutics 11, 111-116

73. Saini N and Schaffner W (2010) Zinc supplement greatly improves the condition of parkin mutant Drosophila. Biol Chem 391, 513-518

74. Guo J, Cui Y, Liu Q et al (2018) Piperine ameliorates SCA17 neuropathology by reducing ER stress. Mol Neurodegener 13, 4

75. Lee MK, Stirling W, Xu Y et al (2002) Human $\alpha$-synuclein-harboring familial Parkinson's disease-linked Ala-53 $\rightarrow$ Thr mutation causes neurodegenerative disease with $\alpha$-synuclein aggregation in transgenic mice. Proc Natl Acad Sci U S A 99, 8968-8973

76. Dalfo E, Gomez-Isla T, Rosa J et al (2004) Abnormal $\alpha$-synuclein interactions with Rab proteins in $\alpha$-synuclein A30P transgenic mice. J Neuropathol Exp Neuron 63, 302-313

77. Lu X-H, Fleming SM, Meurers B et al (2009) Bacterial artificial chromosome transgenic mice expressing a truncated mutant Parkin exhibit age-dependent hypokinetic motor deficits, dopaminergic neuron degeneration, and accumulation of proteinase K-resistant $\alpha$-synuclein. J Neurosci 29, 1962-1976

78. Gasser T (2001) Genetics of Parkinson's disease. J neurol 248, 833-840

79. Kumar R, Jangir DK, Verma G et al (2017) S-nitrosylation of UCHL1 induces its structural instability and promotes $\alpha$-synuclein aggregation. Sci Rep 7, 44558

80. Tran HH, Dang SN, Nguyen TT et al (2018) Drosophila Ubiquitin C-Terminal Hydrolase Knockdown Model of Parkinson's Disease. Sci Rep 8, 4468

81. Kelm-Nelson CA, Brauer AF, Barth KJ et al (2018) Characterization of early-onset motor deficits in the Pink1 $-/-$ mouse model of Parkinson disease. Brain Res $1680,1-12$

82. Cornelissen T, Vilain S, Vints K, Gounko N, Verstreken P and Vandenberghe W (2018) Deficiency of parkin and PINK1 impairs age-dependent mitophagy in Drosophila. eLife 7, e35878

83. Rousseaux MW, Marcogliese PC, Qu D et al (2012) Progressive dopaminergic cell loss with unilateral-to-bilateral progression in a genetic model of Parkinson disease. Proc Natl Acad Sci U S A 109, 15918-15923

84. Li Y, Liu W, Oo TF et al (2009) Mutant LRRK2 R1441G BAC transgenic mice recapitulate cardinal features of Parkinson's disease. Nat Neurosci 12, 826-828

85. Usenovic M, Tresse E, Mazzulli JR, Taylor JP and Krainc D (2012) Deficiency of ATP13A2 leads to lysosomal 
dysfunction, $\alpha$-synuclein accumulation, and neurotoxicity. J Neurosci 32, 4240-4246

86. Giovannone B, Tsiaras WG, de la Monte $S$ et al (2009) GIGYF2 gene disruption in mice results in neurodegeneration and altered insulin-like growth factor signaling. Hum Mol Genet 18, 4629-4639

87. Kim M, Semple I, Kim B et al (2015) Drosophila Gyf/GRB10 interacting GYF protein is an autophagy regulator that controls neuron and muscle homeostasis. Autophagy 11, 1358-1372

88. Martins LM, Morrison A, Klupsch K et al (2004) Neuroprotective role of the Reaper-related serine protease $\mathrm{HtrA} 2 / \mathrm{Omi}$ revealed by targeted deletion in mice. Mol Cell Biol 24, 9848-9862

89. Tain LS, Chowdhury RB, Tao RN et al (2009) Drosophila HtrA2 is dispensable for apoptosis but acts downstream of PINK1 independently from Parkin. Cell Death Differ 16, 1118-1125

90. Zhou Q, Yen A, Rymarczyk G et al (2016) Impairment of PARK14-dependent Ca $2+$ signalling is a novel determinant of Parkinson's disease. Nat Commun 7, 10332

91. Chiu C-C, Yeh T-H, Lu C-S et al (2017) PARK14 PLA2G6 mutants are defective in preventing rotenone-induced mitochondrial dysfunction, ROS generation and activation of mitochondrial apoptotic pathway. Oncotarget 8, 79046-79060

92. Vingill S, Brockelt D, Lancelin C et al (2016) Loss of FBXO7 (PARK15) results in reduced proteasome activity and models a parkinsonism-like phenotype in mice. EMBO J 35, 2008-2025

93. Burchell VS, Nelson DE, Sanchez-Martinez A et al (2013) The Parkinson's disease-linked proteins Fbxo7 and Parkin interact to mediate mitophagy. Nat Neurosci 16, 12571265

94. MacLeod DA, Rhinn H, Kuwahara T et al (2013) RAB7L1 interacts with LRRK2 to modify intraneuronal protein sorting and Parkinson's disease risk. Neuron 77, 425-439

95. Tang F-L, Liu W, Hu J-X et al (2015) VPS35 deficiency or mutation causes dopaminergic neuronal loss by impairing mitochondrial fusion and function. Cell Rep 12, 16311643

96. Yim Y-I, Sun T, Wu L-G et al (2010) Endocytosis and clathrin-uncoating defects at synapses of auxilin knockout mice. Proc Natl Acad Sci U S A 107, 4412-4417

97. Song L, He Y, Ou J et al (2017) Auxilin underlies progressive locomotor deficits and dopaminergic neuron loss in a Drosophila model of Parkinson's disease. Cell Rep 18, 1132-1143

98. Pan P-Y, Li X, Wang J et al (2017) Parkinson's DiseaseAssociated LRRK2 Hyperactive Kinase mutant Disrupts Synaptic Vesicle Trafficking in Ventral midbrain Neurons. J Neurosci 47, 11366-11376

99. Schulze KL, Broadie K, Perin MS and Bellen HJ (1995) Genetic and electrophysiological studies of Drosophila syntaxin-1 A demonstrate its role in nonneuronal secretion and neurotransmission. Cell 80, 311-320 